\title{
Diagnoses of (Con)temporality: J.-F. Lyotard, J.-L. Nancy, M. Krieger, and P. Gilroy
}

\author{
Dr Ewa Bobrowska \\ Academy of Fine Arts, Warsaw, Poland \\ Research paper financed by the Ministry of Science and High Education's
}

"National Program for Development of Humanistic Studies 2014-2019". Grant No 0114/NPRH3/H12/82/2014.

\begin{abstract}
This paper focuses on the comparison of various theories of contemporality that emphasize the categories of time, movement, and contingency. The argument concerns the contemporary philosophy of Jean-François Lyotard, Jean-Luc Nancy, Murray Krieger, and Paul Gilroy. In his paper Time Today Lyotard perceives contemporary consciousness in terms of, extended by modern technology, capacity of implementing the past narratives within the structures of temporality. Meaning proceeds from the emotional attitude toward those past events. In this view, present immigration problems are linked to the issue of space related dimensions of traditional culture and its tendency towards inertia. On the other hand, Lyotard points to a new emerging model of the contemporary technology-based culture, which manages to surpass the obstacles of locality. However, as Lyotard claims, this process, based on the merging of technology, science and culture, does not lead to the increase of educational, economic, and moral standards of society, but instead gives rise to "barbarism, illiteracy, impoverishment of language, new poverty." In reference to Leibniz's concept of a complex monad, Lyotard juxtaposes memory to event claiming that the modern era is characterized by the domination of oppositional forces of rationalizing and contingency. This opposition is analyzed in the light of a comparable concept introduced by Derrida based on the confrontation of the terms: event and machine.Moreover, a postcolonial critic Paul Gilroy in his Postcolonial Melancholia describes contemporary social phenomena with the use of terms conviviality, multiculturalism, immigration, race, globalism, and planetarity, which also encompass contingency and movement.
\end{abstract}

The present moment, as a movement towards transgression of time, the opening, the breach in time, becomes the object of analysis in Adoration by another contemporary thinker, Jean-Luc Nancy. According to him, the enclosure in scientific forms of rationality and reason today produces the counter drive towards the contact with the open.

Temporality and temporal distance is also an issue discussed by Murray Krieger in reference to Paul de Man' $s$ „Rhetoric of Temporality" that focuses on the discontinuity between language and existence, or the void that separates them.

The proposed analysis concerns the discussion of those divergent diagnoses of contemporary society in relation to the issue of time.

In some sense this analysis concerns the phenomenon of the flow or movement (of time, desire, language, blood, refugees, immigration, etc.) as the essence of contemporality. The argument focuses on those elements of postmodern ethics that involve change, instability, and the temporal as the most vital, constituting, and thus constant elements. In other words, it is about new reflection on the ancient problem of the constancy of change, a "recurrent alterity” (Lyotard 2006, 267), according to J. -F. Lyotard. Notably, in his writings, one finds a revealing analysis of the temporal state of postmodern condition. In Time Today, he concentrates on the topic of temporarily and time related aspects of the current condition of modern societies and modern consciousness.

The perception and experience of time have been recognized as one of the most perennial, yet problematic tasks of philosophy since its very beginnings and the ontology of change and becoming proclaimed in Heraclitus's thought. One cannot enter the same river twice, says Heraclitus, attributing the imagery of the principle of constant transformation to fire and its opposite: the flow of a river. 
In reference to a never-ending flow that takes place in every perceptible or indefinitely small segment of time, Lyotard proposes the above mentioned term: „recurrent alterity,” in the face of which one remains a passive observer. This notion points to two opposite aspects of the phenomenon of time: its repeatability (based on some element of sameness) and absolute change (every moment is different). Moreover, each act of perceiving the present is experienced as unique, yet imperceptible: „....) present cannot be grasped as such, it is absolute. It cannot be synthesized directly with other presents. The other presents with which it can be placed in relation are necessarily and immediately changed into presented presents, i.e. past", claims Lyotard. (Lyotard 2006, 266).

These analyses establish the ground for further speculations about the future and present problems the humanity will have to face. The main aim of civilization which Lyotard treats with suspicion is also time-related. The accumulation of information has one goal; it should lead to the subordination of the future to present expectations. Predictability is the key to control, effectiveness, and power in an economic sense. On the other hand, in a philosophical sense, it guarantees and confirms the truth preserved in the techno-scientific discourse, which is a new form of coping with collective memory that was previously invested in the medium of myth. Expanding the capacity of computer stored databased memory and mastering data analyses is a challenge which humanity will have to face in order to "adapt to the growing complexity” of the system and, self-reflectively, to respond to "the growing comlexifying relations between human beings." A perfect monad, according to Lyotard, in reference to Leibniz's theory will finally master and stop the flow of time and information. The state of divine all-knowing will constitute a perfect final stability and an eventual partial overcoming of Heraclitus's paradox of constant change. This will mark the final victory of the machine over the event in Derrida's vocabulary, but this vision possesses also serious drawbacks. Lyotard points to Heidegger's figure concerning technology Gestell and considers it threatening. „Mind and even soul are studied as though they were interfaces in physical processes," he worries (Lyotard, 274). The allencompassing domination of technē leaves no place for what may be termed purposeless (with no purpose outside itself to use Kant's terms) humanistic imagination. In this situation, the uniqueness of the mind and its only rescue is an access to the event celebrated in such mediums of free creation as: the visual arts, everyday language, poetry, music, and literature.

However, as Murray Krieger notes, no work of art or a literary or critical text is innocent and free of institutional constrains or materialistic ideologies. Neither can it be free from ethics. "Everywhere the ,political unconscious' writes texts that are responsive to its (criticism's - EB) will to power,"1 (Krieger 1983, 134) as Krieger notes. A text unfolds in time during the reading process, it unfolds its sense in relation to other texts, using the rhetorical figures to create an illusion of change and repetition. The flow of criticism and theoretical thought that should be more self-conscious forms of language use, is based on awaiting for the truly innovative critical event to arrive unexpectedly as Godot upon the stage of writing in order to radically illuminate present and past readings. Could it come from the outside, that is from the techno-scientific discourse, as Lyotard seems to suspect and break „a Dantean circle of language in which all are damned and none innocent” (Krieger $1983,134) ?$

The other of any critical discourse and (philosophy) is a matter of the future to come, which could complete the growing complexity of the monad. Krieger notes: „There remain, outside, those desires that would shape language to themselves as they seek to shape history in their direction. These subjugate the text to themselves, the subliminal masters that make us distrust all that is said" (Krieger 1983,134), states Krieger.

These are forms of awaiting the un-predictable, in a sense which Lyotard introduces through his famous notion of the unpresentable in "Answering the Question: What is Postmodernism." He also confirms that with the expansion of logic and mathematics to other domains of thought, the problem and paradox of time have shifted to the main position.

Lyotard perceives the contemporary consciousness in terms of, extended by modern technology, capacity to store the past and present narratives or information within the structures of temporality. Meaning proceeds from the emotional attitude towards those events. Collective, emotionally charged memory of any community forms its culture that is always geographically and historically limited, therefore, static. The present immigration problems are linked to the issue of space related dimensions of traditional cultures and their tendency towards inertia. On the other hand, Lyotard points to the new emerging model of contemporary technology-based culture, which manages to surpass the obstacles of locality. This new

1For the discussion of politics as technē see: Langdon Winner' Technē s and Politeia: The Technical Constitution of Society. 
global mode of media culture encourages immigration, as it facilities the circulation of information. However, as Lyotard claims, this process, based on the merging of technology, science and culture, does not lead to an increase of the educational, economic, and moral standards of society, but instead gives rise to "barbarism, illiteracy, impoverishment of language, new poverty." (Lyotard 2006, 270) The new global consciousness and memory are often based on intolerance and stereotypical thinking, leaving no place for any deeper reflection. The movement of complexification and the augmentation of social collective memory based on the digital synthesis of past narratives or times result in losing touch with a singular ego or body. The human race is „pulled forward by this process without possessing the slightest capacity for mastering it," laments Lyotard. (Lyotard 2006, 270).

In reference to, the already mentioned above, Leibniz's concept of a complex monad, Lyotard opposes memory to event, claiming that more complex collective memory offers more control over any (present or future) event /unexpected occurrence. The growing complexity of the system, (of which the event remains the best producer) consists in the progressing in time complexity of social, economic and cultural relations. This forms a model which Lyotard relates to the complexity of time syntheses that, according to contemporary physics, happen only locally. Humanity might be one of those local gatherings of time, which as every result of physical processes is: „temporary and highly improbable." It is more exciting says Lyotard to think about humanity in this astronomic perspective, "to think that what is called research and development in the contemporary societies (...) are much more the result of such process of ,cosmolocal' complexification" (Lyotard 2006, 268) than the result of a progress towards more happiness and social justice. The modern era is characterized by the domination of oppositional forces of rationalizing and contingency. It gives preference to new language uses based on rationalization, logic, pragmatism and communicational efficiency at the expense of the poetic, notes Lyotard.

In his essay „Typewriter Ribbon”, Derrida proposes a pair of opposites: the patterns of the machine as opposed to the logic of event, comparable to the already discussed antinomies of memory and event. It refers to what was once the future time and its accordance with the previous desire or prediction. The event is structured according to the logic of deconstruction with reference to de Man's notion of the material event. The happening of the event is always external to the present, it is the outside of desire, according to Derrida, rapture, some unpredictable course of events, the dissolution and the bankruptcy of our expectations and strategies. It is the other of time, which constitutes its forever tragic yet intriguing dimension. Tragic in a sense of the alienation of the subject of desire, its estrangement towards itself, which as Derrida and Ihab Hassan note, cannot escape the tragic tone since it always precludes the possibility of what is the most and the least possible that is the event of death. Hassan's analysis of cultural innovation focuses on the paradox of death, an „even of events” (Hassan 1983, 15) as a driving force of change and desire. In „Ideas of Cultural Change” Hassan comments:

In short, more than an existential metaphor, more than an ontology of the new or a politics of innovation, death enters every language by which we try to understand change; and it acts, as Heidegger saw, as the basis of ,authentic history,' which finds its weight not in the past, not in the "today," but in the Geschehen, the very process of existence, originating from the future, the „Being-toward-death. (Hassan 1983, 17).

Also Murray Krieger demonstrates how the purely theoretical reflection on language necessarily carries within itself an existential message about the temporality of human condition always ending in death. In his analysis of Paul de Man's criticism, he claims:

For de Man's, what is celebrated in a word is its "pure anteriority," which renounces "the desire to coincide" with "another sign that precedes it," instead accepting its "temporal difference," "its authentically temporal predicament" (pp. 190-91). But the last word, "predicament," opens language outward to the human condition: the fate of being only temporal starts by belonging to a sequence of words but shifts to the consecutive, unrepeatable moments of our lives. And with the prohibition against the spatiality of a return, against any simple repetition, the moments can only run out, following one another to death. (...) The semiotician in de Man cannot abandon the existentialist in him: treating the verbal sign as that which keeps us from touching our existential fate, he is simultaneously showing that language can contain that existential fate, though as a negative vision. (Krieger 1983,128-9)

However, the tragic materiality of desire should not be treated as an unsubstantial metaphor or a signifier without a signified as during the course of history, it can assume an appalling form of massive war crimes. In Klaus Theweleit's theory of suppressed desire, the inferior position of women in the society and the subsequent deepening of the gap between the 
sexes, their social, cultural, and emotional separation manifested itself in a murderous but irresistible man's death drive, the call of blood, the desire to penetrate the body of the other by turning into a bloody mass. As if in response to such traumatic disasters, Derrida claims: „every event as such is traumatic. Even an event experienced as a ,happy” one. (...) Understood in this sense, trauma is that which makes precarious any distinction between the point of view of the subject and what is produced independently of desire". (Derrida 2001, 358) The secrecy and mystery of time involves constant change and the creation of the impossible transformations of desire. A more optimistic diagnosis of postmodern transformation of desire is to be found in the writings of another contemporary French philosopher Jean-Luc Nancy.

All the above mentioned figures and forces may be expressed in terms of movement, change, transition, flow, the flow of a stream (of desire or information in a contemporary society). The present moment is always in movement towards the transgression of time, the opening, the breach in time and a conceptual bridge over the past and future, according to JeanLuc Nancy. He focuses on the individual rather than on the general as Lyotard, and, interestingly enough, draws attention to the „pathological dependency” (Nancy 2013, 8) emotional or sensual (but not intellectual) insufficiency of contemporary men and women. This desire for experience results in addictions, a phenomenon characteristic to our society, according to Nancy. The enclosure in scientific forms of rationality and reason today, produces a counter drive towards openness, "for the contact with the open" (Nancy 2013, 8), the Absolute of the desire according to Nancy, that is God.

Analyzing the psychological and intentional dimension of the development of civilization, Nancy notes another interesting and usually underestimated transformation of desire that is the drive to sense. It is the only motivation that can overcome and „displace the regime of power and money as we know it." (Nancy 2013, 60) In this way, Nancy proclaims the triumph of thinking over pragmatism, materialism and politics, as according to his account the domain of sense should not be limited only to knowledge, reason, and technical solutions, but it should encompass the development of the sphere of mutual communication and trust based on Christian faith and "the common experience of language as ,we.' "The drive towards sense is the most vital force shaping societies and individual human beings. It is an irrational, mystic flow of desire and energy, it is "the tension and thrust coming from the force that separates the world from elsewhere (...) a drive of being, being as a drive in whose charge we find ourselves" (Nancy 2013, 61).

The sense of being, or more generally understanding being as sense, does not necessarily contribute to the one-directional progress of humanity, as it may take a form of the collapse of a civilization. Instead, sense relies on establishing relation by observing the law of the universal love of others: this is "the possibility, the power, and the dynamics of relation" (Nancy $2013,60)$. This universal sense of being forms the foundation of any true globalist thought and society. It thrusts our imagination towards the vision of the world in its totality, and forces thinking in ethical and existential terms of relation and common language, instead of criteria of power and possession. It is such a powerful force that the introduction of the drive towards sense, which Nancy associates with the beginning of Christianity, at first brought about the breakdown of the old civilization. The collapse of the Roman Empire was according to Nancy, the consequence of the current social, political, cultural, and economic system, which marginalized or excluded the need for forming „relation of people to each other and to the world". Therefore: "the order of Rome, however imposing its success might have been, ended up no longer recognizing itself as a possibility of sense", claims Nancy (Nancy 2013,54). A similar crisis, surfacing with the advent of the politics of exclusion, isolation and indifference to the suffering other, may be faced by the contemporary seemingly potent Western societies. The truth that we cannot escape is that the refusal to accept and respond to the need of the other, often an immigrant in this case, opening and sharing our language with the language of the other, will diminish our own chances of "recognizing ourselves as a possibility of sense," reminds Nancy. The drive towards sense should pervade the present and guarantee the future of every true existence of a genuinely human society.

Not surprisingly, Nancy depicts the drive to sense in terms of a mystical movement of change that transgresses the individual subject. We are experiencing it while being immersed and carried by the stream of this drive. The only requirement is to remain open, submissive, and responsive to its flow. Nancy describes the drive with reference to the imagery of light and stream:

Drive, a thrust coming from elsewhere, from outside, from nowhere, which opens up in us; which comes from there but which, at the same time, opens up this unlocalizable place; which comes from mystery and produces it, which triggers its flash and goes back into its night: to the absence of solution, to the dis-solution where truth resides. But in this truth is kept and saluted the existence of everyone; the impulsion of relation and the pulsation of sense: it comes and goes from one to 
the other, from some to others, without establishing any continuity of being but rhyming our common presence- our coappearance and our exposure [exposition] (Nancy 2013, 61)

Klaus Theweleit refers to the red flood of ideology (that according to Nazi threatened German national, political and cultural identity) which had to be counterbalanced and drawn in a red flood of blood. In contemporary societies the flow of desire is parallel to the flow of information in the multiple and tiny subcutaneous veins of the Internet. The medium of flowing water, a stream is a well-established symbol of time, dating back to the already mentioned, Heraclitus's famous paradigm of a flowing stream which can never be entered twice in the same state and moment. In his analysis of Heidegger's topography, J. Hillis Miller confirms: "the stream is, of course, also a way of expressing temporality, for example, in Heraclitus's fragments" (Miller 1995, 149).

Water, in its timeless quality, constitutes an archaic source of life immersed in the depth of time. Its surface reflects the current passing image, temporary and unstable, bound to fall into oblivion as it disappears in the next moment. It is devoid of the solid, lasting form and quality of earth. According to the Biblical imagery, in the beginning "the Spirit of God was hovering over the surface of the waters." (New American Standard Bible 1995, 5). In Heidegger's view, the depth of time archaic, pre-Socratic thinking formed the original authentic inside to the truth of existence as the depth of oceans formed the origin of life. Interestingly enough, Heraclitus's authority and his reference to water are invoked by Heidegger in his Building Dwelling Thinking. Heidegger's symbol of the bridge, may refer to an attempt of imposing some spatial organization upon the disorder and unpredictability of the stream. In Derrida's imagery this opposition could be parallel to the antinomy of the machine and event. The machine as symbolizing the effect of the technē principle at work (for example in the construction of the bridge), as well as in the repetitive, mechanical actions of crossing the bridge. Therefore the mechanical will always happen within the measureable time dimensions as opposed to the timelessness of the event of flowing.

Derrida proposes a similar metaphor in another paper entitled "Some Statements and Truisms about Neologisms, Newisms, Postisms, Parasitisms, and Other Small Seismisms." In this text, the bridge is only one-sided and called jetty. It is a seawall that protects the hitherto acquired theoretical constructions of philosophical and critical thinking against the unknown and yet unthinkable future. Derrida stresses that different jetties, as various ways of theoretical and political ordering of the present, are competitive. Therefore, the present moment is always determined by the domination of one mechanistic jetty or bridge that directs the current journey through time. As an interesting example of a sociological application of the philosophical concept of jetty, one may point to Derrida's lecture on geopsychoanalysis. It concerns the problem of racism in South Africa based on the absurd declaration quoted in his "Racism's Last Word” promoting "the separate development of each race in the geographic zone assigned to it" (Derrida 2007, 378). In relation to the discussion of the territory of dwelling, there emerges a question of the possession of land, borders, boundaries, and barriers. In this context, the figure of the bridge or jetty signifies the opening of isolated physical and mental zones in order to facilitate the free, unrestricted movement of bodies and ideas. In a sociological sense, the indeterminable flow of water and its tendency towards mixing in order to form equilibrium refer to the flow of human masses that is migration movements. Time serves in this case as a very effective model and factor contributing to the transformation, deconstruction, or dissolution of once established strict spatial, political, and cultural partitions, or meanings as Derrida has it. It especially concerns those words that institute discrimination and cruelty. In "Racism's Last Word” Derrida reconsiders the meaning and the abstract scope of mental territory occupied by the word: „apartheid." He notes:

(...) by itself the word occupies the terrain like a concentration camp. System of partitions, barbed wire, crowds of (...) solitudes. Within the limits of this untranslatable idiom, a violent arrest of the mark, the glaring harshness of abstract essence (heid) seems to speculate on another regime of abstraction, that of confined separation. (...) By isolating being apart in some sort of essence or hypostasis, the word corrupts it into a quasi-ontological segregation. In any case, like all racisms, it tends to pass segregation off as natural- and as the very law of origin. Monstrosity of this political idiom. (Derrida 2007, 334)

Derrida's argumentation concerns the stabilizing and creationist power of language, which in this case, he recognizes as a dangerous pervasion.

The mechanistic effect of inertia of the unjust system could be overcome by processes that have to do with Gilroy's term conviviality: interexchange, progress, event, innovation, and democratization. The same applies to the process of overcoming the communist totalitarian regime in the 80 s in Poland and the subsequent wave of liberation reaching other 
currently post-communist countries. Notably, the power and the stagnancy of this regime were based on the spatial and cultural isolation of the country. Hermetically closed borders, totalitarian control over the information circulating in the media, no access to the outside world form the basis of any potentially dangerous geopolical closure.

Therefore, the rebirth of antiglobalistic tendencies towards nationalistic separatism in Europe and the US should raise our critical awareness. It is evident in the recent event of the United Kingdom withdrawing from the European Union and the absurd idea of building a wall at the Mexican border to protect California, which resembles Nazi idea of erecting the ghetto wall isolating Jews in Warsaw. Notably, in both cases the costs of isolation are paid by the victims.

In his book published in 2005, Paul Gilroy talks about the political and social situation of the Great Britain and other countries. His diagnoses have recently been confirmed by Brexit, anti-immigration policies, and violent acts against immigrants. The postcolonial melancholia, referred to in the title, designates a new context for the notion of the mental state of melancholia described by Freudian psychoanalysis. It concerns to the general state of nation rather than the state of an individual psychic, affected and dominated by contemporary neoimperialistic tendencies. As an alternative for the state's state of melancholia, Gilroy proposes the values of conviviality and planetarity. Conviviality does not take place in a mature cosmopolitan society. Rather, it designates a community, which evolves towards this ideal. It has to do with cohabitation and the possibility of establishing relation. It is a term that implies a passage of time: time equal to man's life time, simultaneous, open and harmonious times happening within one community. As Gilroy notes: „it does not describe the absence of racism or the triumph of tolerance. Instead it suggests a different setting for their empty, impersonal rituals, which (...) have started to mean different things in the absence of any strong belief in absolute or integral races. (Gilroy $2005, X V)$. Planetarity which Gilroy proposed in the place of globality has more dynamic and time-related dimensions implying contingency and movement. The author diagnoses Britain as especially prone to imperialist thinking due to its colonial past. His analysis, however, is not limited to only one symptom of community's neurosis. Freud's analysis, treated perhaps too uncritically in Gilroy's text, acknowledges that the place for unavoidable conflicts, the discharge of distractive energy in happening that racism creates, are necessary. Moreover, the impossibility of the principle of love of neighbour is affirmed. To propose a possible solution to this ethical impasse, Freud points to a need for developing a special approach to analyse and understand the mechanism of forming "the pathology of cultural communities"'” (Gilroy 2004, 65).

However, as Gilroy notes, we should bear in mind that the problems of violence, discrimination, racism, and master-slave division cannot be diagnosed solely in reference to contemporality, because they have accompanied humanity since its very beginning. For example, some early feminist undertones can be traced in Montesquieu's novel Persian Letters that describes a revolt of wives in a Persian harem. In the writings of Montesquieu (notably a devoted traveller), DuBois and Gandhi, Gilroy locates the first attempts to conceptualize and create a universal planetary consciousness or cosmopolitanism based on solidarity. Therefore, to form a new humanism, humanity is obliged to look back and analyse the incessant flow of blood and violence caused by its numerous mistakes, such as: fascism, colonial imperialism, slavery, war crimes and murders, racial and sexual discrimination, etc. As Gilroy notes: „this is a planetary consciousness of the tragedy, fragility, and brevity of indivisible human existence that is all the more valuable as a result of its openness to the damage done by racism.” (Gilroy 2004, 75). "The detour through modern histories of suffering must be mandatory" (Gilroy 2004, 151), he adds elsewhere. Yet, the world conflicts caused by imperialistic claims such as Russian-Ukraine, or, analysed by Gilroy, Israeli-Palestinian conflicts, give also rise to new theories supporting them and paving the way for a rebirth of an imperial catastrophe, worries Gilroy. A seemingly modern problem of migration, he notes, has always been a part of Europe's history and, therefore, we need a serious search for a new language and new phraseology that do not discriminate between a citizen and the other, European and non-European. To deconstruct the binary, simplified oppositions that prepared the ground for ethnic conflicts is to realise that, as Heraclitus taught, every pair of oppositions is only temporary.

Finally, let me note that the term "mobile multiplicity," proposed by Derrida in reference to his own writings, may offer a solution also in political or sociological dimensions of its meaning:. It is a "movement that engenders by giving form or the figure that gathers up a mobile multiplicity: configuration in displacement. A formation must move forward but also advance in a group" states Derrida. (Derrida 2007, XII) This is an adequate figure of a new, ideal, mobile society based on cosmopolitanism and conviviality that remains open to the call of time, change, and event. 


\section{References:}

[1] de Man, Paul (1971), „Rhetoric of Temporality”, in Blindness and Insight: Essays in the Rhetoric of Contemporary Criticism, Minneapolis: University of Minnesota Press.

[2] Derrida, Jacques (2007), Psyche. Invention of the Other, Vol. 1, Stanford: Stanford University Press.

[3] Derrida, Jacques (1989), "Some Statements and Truisms about Neologisms, Newisms, Postisms, Parasitisms, and Other Small Seismisms", in The States of Theory, New York: Columbia University Press.

[4] Derrida, Jacques (2001), „The Typewriter Ribbon", in Material Events. Paul de Man and the Afterlife of Theory, Minneapolis, London: University of Minnesota Press.

[5] Gilroy, Paul (2004), Postcolonial Melancholia, New York: Columbia University Press.

[6] Hassan, Ihab (1983), „Ideas of Cultural Change”, in Innovation/Renovation. New Perspectives in the Humanities, Madison: The University of Wisconsin Press.

[7] Heidegger, Martin (1996), Being and Time, Albany: State University of New York Press.

[8] Heidegger, Martin (1971), „Building Dwelling Thinking”, in Poetry, Language, Thought, New York: Harper Colophon Books.

[9] Heidegger, Martin (1977), The Question Concerning Technology and Other Essays, New York: Harper.

[10] Kant, Immanuel (2000), Critique of the Power of Judgment, Cambridge and New York: Cambridge University Press.

[11] Krieger, Murray (1983), „In the Wake of Morality: The Thematic Underside of Recent Theory”,

[12] New Literary History, Vol. 15, No. 1, Literature and/as Moral Philosophy, pp. 119-136.

[13] Lyotard, Jean-François (2006), „Answering the Question: What is Postmodernism?”, in The Lyotard Reader\&Guide, New York: Columbia University Press.

[14] Lyotard, Jean-François (2006), „Time Today”, in The Lyotard Reader\&Guide, New York: Columbia University Press.

[15] Miller, J. Hillis (1995), Topographies, Stanford: Stanford University Press.

[16] Nancy, Jean-Luc (2013), Adoration. The Deconstruction of Christianity II, New York: Fordham University Press.

[17] New American Standard Bible (1995), La Habra: The Lockman Foundation Press.

[18] Winner, Langdon (1983), „Technē and Politeia: The Technical Constitution of Society”, in Philosophy and Technology, Boston Studies in Philosophy of Science, New York: Springer.

[19] Theweleit, Klaus (1987), Male Fantasies, Minneapolis: Minnesota University Press. 